\title{
Contrast-Filled Balloon Guided Needle Puncturing in the Presence of Ipsilateral Subclavian Vein Occlusion
}

\section{Sharifkazemi $\mathbf{M}^{*}$, Rezaian $\mathbf{G}$ and Sayyad M}

Cardiology Department, Nemazee Hospital, Zand Blvd, Shiraz, Iran

*Corresponding author: Sharifkazemi M, Associate Professor of Medicine, Cardiology Department, Nemazee Hospital, Zand Blvd, Shiraz, Iran, Tel: +989171110514; Email: dr.sharifkazemi@gmail.com

Received: November 30, 2018; Accepted: December 17, 2018; Published: December 24, 2018

Copyright: ( $) 2018$ Sharifkazemi M, et al. This is an open-access article distributed under the terms of the creative commons attribution license, which permits unrestricted use, distribution, and reproduction in any medium, provided the original author and source are credited.

\section{Abstract}

Aim: The purpose of this report is to convey our experience with the use of the new technique for the safe needle puncturing in the subclavian or brachiocephalic vein in patients with ipsilateral venous obstruction.

Methods: In the time period from June 2016 to June 2018, eleven patients who were candidates for implantation or upgrading of cardiac implantable electronic devices enrolled to do this technique; all patients which were showed to have subclavian vein obstruction through ipsilateral phlebography. By introducing the guiding catheter from femoral vein into the brachiocephalic vein, doing retrograde brachiocephalic venography, followed by passing of the guidewire, the over the wire balloon tracked the guidewire and was placed in a proper location.

Results: The balloon filled with contrast and worked as a landmark for needle puncturing. Between one to three attempts needle puncturing were performed to get to the vein successfully. Then, the valve peel away sheath(s) was/were indwelled over the anterograde guidewire that introduce through the needle and finally the lead(s) was/ were placed in the standard fashion. There were no complications at all and the procedure prevented time wasting.

Conclusion: Contrast-filled balloon guided needle puncturing technique in the presence of ipsilateral subclavian vein obstruction is a safe and feasible method.

Keywords: Ipsilateral subclavian vein obstruction; Retrograde subclavian/brachiocephalic phlebography; Contrast filled balloonguided venepuncture

\section{Introduction}

The first time that the pacemaker was embedded with surgical technique was by Senning and Elmqvist in Sweden on 8th October 1958. They used a thoracotomy to suture two epicardial electrodes and the 'definitive' unit placed in the abdominal wall of the pacemaker recipient. For years hence, surgeons played a role in pacemaker implantation until this was done non-surgically by cardiologists as technology progressed and the size of generators decreased.

And as time passes, the cardiac patient's longevity has increased, and with the advent of ICD and CRT, those have larger generators as well as multiple leads and often with larger caliber leads which they should ultimately pass through the subclavian vein to reach the heart chambers. Over time, the cardiologist who implants cardiac implantable electronic devices (CIEDs) has faced more problems, especially in younger and slimmer patients that have less subclavian vein calibre which ultimately increase the chance of stenosis or obstruction of the subclavian vein after lead(s) insertion into the SCV.

The methods of finding a suitable vein to reach the proper places for non-surgical cardiac leads insertion are numerous: Percutaneous needle vein puncturing such as cephalic, axillary, or subclavian vein approach. However, the leads in either vein puncture technique that are chosen would eventually pass through the subclavian vein
Meanwhile, there is a priority for left-sided approaching due to the greater number of right-handed patients in the population.

Anatomically, the intersection of the two veins, the first from the bottom and the depth, "the axillary vein", and the second from the above and superficial, "the cephalic vein", make the veins that are called the subclavian vein after crossing the outer edge of the first rib. Then, the intersection of the subclavian vein with the internal jugular vein is the constructor of the brachiocephalic vein, which, unlike the artery that is just on the right side, is bilateral in veins [1,2] (Figure 1).

Historically, in 1952, Aubaniac R, introduced the subclavian vein puncture technique for the first time [3]. Now-a-days, the way in which the subclavian vein is punctured is usually at the intersection of the first rib and the clavicle under fluoroscopy. However, in some cases, using the contrast agent for phlebography, simultaneously checks the path of the vessel open and, on the other hand, it will help the performer to get to the vein by following the road map technique, with less possibility of complication such as pneumothorax [4].

On the other hand, in cases of ICD and/or CRT-D devices, where we prefer placing the generator into the pocket in the left side, in front of the pectoralis major muscle or sub pectoral in emaciated patients [5], targeting the heart is more effective in the centre of electrical circuit for cardiac shocks. Also, it is always easier through the left side approach technically, for intubating the coronary sinus ostia and inserting the CS lead inside the vein and putting it in the desired branch to reduce the dyssynchrony. Additionally, the CS lead would be more stable, and its positional stability made more durable. 


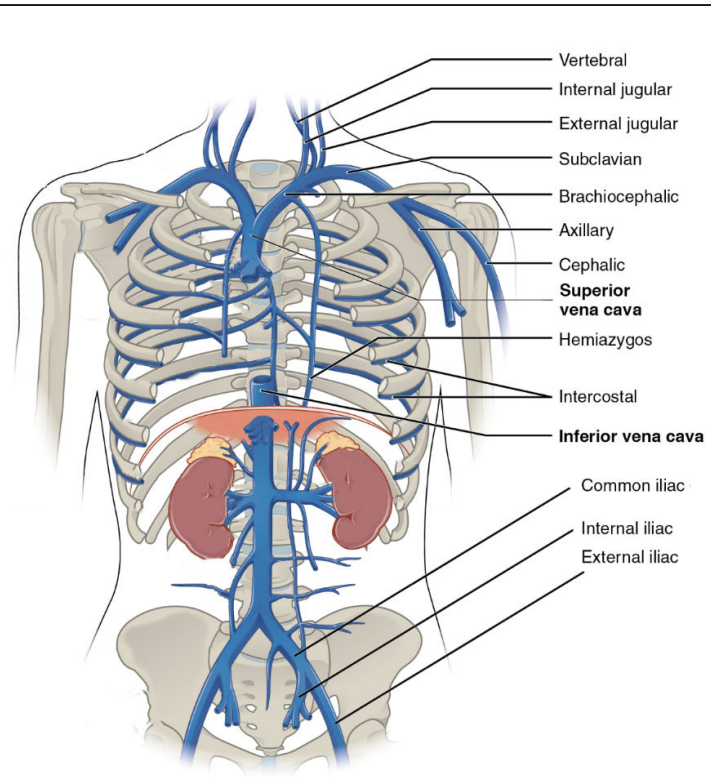

Figure 1: Normal anatomy of upper thoracic veins with focus on the left sided major veins and their relation to the chest cage bones. Image modified by author. From Anatomy and Physiology by Rice University. Licensed under a Creative Commons Attribution 4.0 International License. (c) 1999-2016, Rice University.

However, the problem occurs when we encounter subclavian vein obstruction. Whether the patient's problem is due to prolonged or frequent stay in the hospital and taking different drugs through the intravenous cannula locating in the upper limbs, or, in the second group, those who have already had SCV lead insertion done for them, and who are in the device upgrade program, have suffered from subclavian vein occlusion, and in this second group, the incidence is up to $9.0 \%$ [6].

In another prospective article that was reported by Petri Korkeila from Finland in 2007, 150 patients underwent implantable cardioverter defibrillator or pacemaker implantation and were followed for six months, the prevalence of subclavian stenosis and/or thrombosis which has approved by contrast injections were $14.0 \%$ [7].

\section{Methods}

In the time period from June 2016 to June 2018, there were a number of patients who came to our centre to implant new or upgrade the cardiac implantable electronic devices (CIEDs), meanwhile, there were eleven patients with difficulty among them. All those eleven patients, except one who suffered from marked obesity with prolonged hospital stay, had previously had lead (s) inserted into the subclavian vein for them. Ipsilateral peripheral injection of the contrast agent was used to find out the venous route, as well as to ensure the openness of the vein route before attempting to puncture the subclavian vein. A remarkable point in our patients with occluded subclavian vein, also included in the Haran Burri's article [8], was that none of them had a superficial collateral vein in the exam.

So, from the outset, we anticipated that we should repeat punctures blindly, which, inevitably, raised the risk of complications, such as pneumothorax. Our method of dealing with partial or complete obstruction of the subclavian vein that were revealed after doing peripheral phlebography, was to avoid puncturing blindly as to not increase the risk of work-related complications. In other words, for all of those patients, which were a total of eleven (Table 1), we used the technique that is outlined in the next section.

\section{Description of the Technique}

The following six-step process was used during the procedure:

\section{Retrograde entry of the guiding catheter}

We put the number seven $\mathrm{F}$ sheath into the femoral vein and introduced the guiding catheter which tracks the $0.035^{\prime \prime}$ guidewire to reach the left brachiocephalic vein, sequentially passing through the iliac vein, inferior vena cava, right atrium and superior vena cava. Then we performed retrograde localized phlebography by $20 \mathrm{cc}$ contrast agent injection (visipaque $300 \mathrm{mg}$ ).

\section{Retrograde introducing the guidewire}

By using hydrophilic guidewire $0.035^{\prime \prime}$ (180 cm length), and if not possible, with the help of the hydrophilic guidewire 0.014 " $(300 \mathrm{~cm}$ length), we went forward, as far as possible, to the proximal part of the subclavian vein retrogradely.

\section{Choosing the balloon type}

In cases where the entire vein was completely obstructed, we usually used the over the wire (OTW) noncompliant peripheral balloon, and in cases of partial occlusion, the over the wire coronary balloon.

\section{Balloon filling by contrast agent}

Then the balloon was filled by contrast agent (visipaque $300 \mathrm{mg}$ ); contrast-filling balloon is done for two reasons: first, in a threedimensional space, targeting the balloon with a standard needle is easier, and, the second goal, this act reduces the number of needle puncturing to a range of 1-3.

\section{Balloon guided needle puncturing}

Then the balloon-guided puncturing was performed by needle $18 \mathrm{G}$ and upon the arrival of blood in the syringe, the tip of the needle would be inside the vein, and eventually allowed the passage of the guidewire $0.035^{\prime \prime}$ and insertion of the intravenous valve peel away sheath(s) easily and uneventfully.

\section{Retrieval of the retrograde guiding catheter and its adjuvants}

After ensuring the insertion of the sheath(s) into the subclavian or brachiocephalic vein, the entire guidewire, the balloon and the guiding catheter were retrieved from the femoral sheath.

\section{Results}

Eleven patients were attempted, all of them with subclavian vein near complete obstruction (7 out of 11) or total complete obstruction (4 out of 11). The length of time from the first lead insertion in the study patients to these procedures was from one to seven years in ten patients. 
Page 3 of 5

\begin{tabular}{|c|c|c|c|c|c|c|c|c|c|c|c|}
\hline $\begin{array}{l}\text { Case } \\
\text { No. }\end{array}$ & Gender & Age & $\begin{array}{l}\text { Reason } \\
\text { procedure }\end{array}$ & $\begin{array}{l}\text { The } \\
\text { last } \\
\text { time of } \\
\text { the } \\
\text { first } \\
\text { implant } \\
\text { ation } \\
\text { (years) }\end{array}$ & $\begin{array}{l}\text { No. of } \\
\text { chronic } \\
\text { leads }\end{array}$ & $\begin{array}{l}\text { No. of } \\
\text { added } \\
\text { leads }\end{array}$ & $\begin{array}{l}\text { Site of vein } \\
\text { occlusion }\end{array}$ & $\begin{array}{l}\text { OTW } \\
\text { balloon } \\
\text { size } \\
\text { which } \\
\text { used }\end{array}$ & $\begin{array}{l}\text { Guidewir } \\
\text { e } \\
\text { calibre } \\
\text { which } \\
\text { used }\end{array}$ & $\begin{array}{l}\text { Type of } \\
\text { guiding } \\
\text { catheter }\end{array}$ & $\begin{array}{l}\text { No. of } \\
\text { needle- } \\
\text { puncturing } \\
\text { to get vein }\end{array}$ \\
\hline 1 & Male & 64 & $\begin{array}{l}\text { ICD-VR Lead } \\
\text { fracture }\end{array}$ & 3 & 1 & 1 & $\begin{array}{l}\text { Distal to mid } \\
\text { subclavian } \\
\text { vein }\end{array}$ & $\begin{array}{l}3.5 \times 25.0 \\
\mathrm{~mm}\end{array}$ & $0.014 "$ & $\begin{array}{l}\mathrm{JR} \\
6.0 \mathrm{~F} \times 3.5 \mathrm{~cm}\end{array}$ & Twice \\
\hline 2 & Female & 72 & $\begin{array}{l}\text { PPM upgrading } \\
\text { to } \\
\text { CRT-D }\end{array}$ & 4 & 1 & 2 & $\begin{array}{l}\text { Distal to mid } \\
\text { subclavian } \\
\text { vein }\end{array}$ & $\begin{array}{l}3.0 \times 20.0 \\
\mathrm{~mm}\end{array}$ & 0.014" & $\begin{array}{l}\mathrm{JR} \\
6.0 \mathrm{~F} \times 3.5 \mathrm{~cm}\end{array}$ & Thrice \\
\hline 3 & Female & 29 & $\begin{array}{l}\text { PPM upgrading } \\
\text { to } \\
\text { CRT-D }\end{array}$ & 6 & 2 & 2 & $\begin{array}{l}\text { Distal to mid } \\
\text { subclavian } \\
\text { vein }\end{array}$ & $\begin{array}{l}3.0 \times 25.0 \\
\mathrm{~mm}\end{array}$ & 0.014" & $\begin{array}{l}\text { NIP } 7.0 \mathrm{~F} \\
\text { MB1 curve }\end{array}$ & $\begin{array}{l}\text { Twice (double } \\
\text { wiling } \\
\text { technique) }\end{array}$ \\
\hline 4 & Female & 64 & $\begin{array}{l}\text { PPM-SR } \\
\text { upgrading to } \\
\text { CRT-D }\end{array}$ & 4 & 1 & 2 & $\begin{array}{l}\text { Distal to mid } \\
\text { subclavian } \\
\text { vein }\end{array}$ & $\begin{array}{l}3.0 \times 20.0 \\
\mathrm{~mm}\end{array}$ & 0.014" & $\begin{array}{l}\text { 110 6.0 F } \\
111: 131 \text { curve }\end{array}$ & $\begin{array}{l}\text { Once (double } \\
\text { wiling } \\
\text { technique) }\end{array}$ \\
\hline 5 & Female & 66 & $\begin{array}{l}\text { ICD —VR lead } \\
\text { upgrading to } \\
\text { CRT-D }\end{array}$ & 4 & 1 & 2 & $\begin{array}{l}\text { Distal to mid } \\
\text { subclavian } \\
\text { vein }\end{array}$ & $\begin{array}{l}3.5 \times 30.0 \\
\mathrm{~mm}\end{array}$ & 0.014" & $\begin{array}{l}\mathrm{JR} \\
7.0 \mathrm{~F} \times 3.5 \mathrm{~cm}\end{array}$ & Twice \\
\hline 6 & Male & 33 & $\begin{array}{l}\text { PPNI-SR lead } \\
\text { fracture }\end{array}$ & 1 & 1 & 2 & $\begin{array}{l}\text { Whole } \\
\text { subclavian } \\
\text { vein }\end{array}$ & $\begin{array}{l}5.0 \times 35.0 \\
\mathrm{~mm}\end{array}$ & $0.035^{\prime \prime}$ & $\begin{array}{l}\mathrm{JR} \\
7.0 \mathrm{~F}^{\star} 3.5 \mathrm{~cm}\end{array}$ & Twice \\
\hline 7 & Male & 75 & $\begin{array}{l}\text { PPM-SR lead } \\
\text { failure }\end{array}$ & 1 & 1 & 2 & $\begin{array}{l}\text { Distal to mid } \\
\text { subclavian } \\
\text { vein }\end{array}$ & $\begin{array}{l}3.5 \times 25.0 \\
\mathrm{~mm}\end{array}$ & 0.014" & $\begin{array}{l}\mathrm{JR} \\
6.0 \mathrm{~F}^{\star} 3.5 \mathrm{~cm}\end{array}$ & Twice \\
\hline 8 & Female & 68 & $\begin{array}{l}\text { PPM-SR } \\
\text { upgrading to } \\
\text { ICD-DR }\end{array}$ & 7 & 1 & 2 & $\begin{array}{l}\text { Whole } \\
\text { subclavian } \\
\text { vein(partially) }\end{array}$ & $\begin{array}{l}3.5 \times 20.0 \\
\mathrm{~mm}\end{array}$ & 0.014" & $\begin{array}{l}\text { MP 6.0 F } \\
\text { 111B1 curve }\end{array}$ & Twice \\
\hline 9 & Female & 56 & $\begin{array}{l}\text { ICD-VR } \\
\text { upgrading to } \\
\text { CRT-DR }\end{array}$ & 2 & 1 & 3 & $\begin{array}{l}\text { Whole } \\
\text { subclavian } \\
\text { vein }\end{array}$ & $\begin{array}{l}5.5 \times 40.0 \\
\mathrm{~mm}\end{array}$ & 0.035 " & $\begin{array}{l}\text { ALP } 6.0 \mathrm{~F} \\
\text { MB' curve }\end{array}$ & Thrice \\
\hline 10 & Female & 82 & $\begin{array}{l}\text { PPM-SR } \\
\text { upgrading to } \\
\text { CRT-P }\end{array}$ & 5 & 1 & 2 & $\begin{array}{l}\text { Distal to mid } \\
\text { subclavian } \\
\text { vein }\end{array}$ & $\begin{array}{l}3.5 \times 20.0 \\
\mathrm{~mm}\end{array}$ & 0.014" & $\begin{array}{l}\mathrm{JR} \\
6.0 \mathrm{~F} \times 3.5 \mathrm{~cm}\end{array}$ & Twice \\
\hline 11 & Male & 74 & $\begin{array}{l}\text { ICD-DR } \\
\text { implantation }\end{array}$ & - & nil & 1 & $\begin{array}{l}\text { Whole } \\
\text { subclavian } \\
\text { vein }\end{array}$ & $\begin{array}{l}6.0 \times 30.0 \\
\mathrm{~mm}\end{array}$ & 0.035" & $\begin{array}{l}\mathrm{JR} \\
6.0 \mathrm{~F} \times 3.5 \mathrm{~cm}\end{array}$ & Thrice \\
\hline
\end{tabular}

PPM-SR; Single Chamber Pacemaker, PPM-DR; Dual Chamber Pacemaker, ICD=Implantable Cardioverter Defibrillator, ICD-VR; Single Chamber Defibrillator; ICDDR; Dual Chamber Defibrillator, CRT-D; Cardiac Resynchronization Therapy with Defibrillator, CRT-P; Cardiac Therapy without Defibrillator, OTW Balloon; Over the wire Balloon, JR Guiding Catheter; Right Judkins Guiding Catheter, MP Guiding Catheter; Multipurpose Guiding Catheter. F Gauge; French Gauge (1F=0.33 nun).

Table 1: Patients' and procedural characteristics.

The clinical characteristics of the study patients are listed in detail in Table 1. To reach the balloon, the number of needle puncturing was respectively: once in one patient, twice in seven patients and three times in three patients. To reduce the number of needle punctures, we used the double wire method in three patients. This is achievable by introducing a sheath over the guidewire, taking out the dilator, putting the second guidewire into the introducer sheath and taking out the whole introducer sheath. Therefore, two guidewires remained inside the subclavian vein, we can introduce one valve peel away sheath over each wire and then use it for each lead in turn separately [9]. Al procedures on eleven patients were successful and none of them had acute complications such as pneumothorax and bleeding or subacute complications such as infection (Figures 2 and 3 ).

\section{Discussion}

It is always awful for an electrophysiologist to have to implant, upgrade or re-implant a device for a patient who suffers from subclavian vein occlusion, because the doer will encounter a timeconsuming job and be anxiously concerned for the increased risk of complications. Incidental finding of subclavian vein obstruction was reported about $0.6 \%$ [10] and even $10.0 \%$ in patients under 
haemodialysis program with negative history of catheter placement [11].

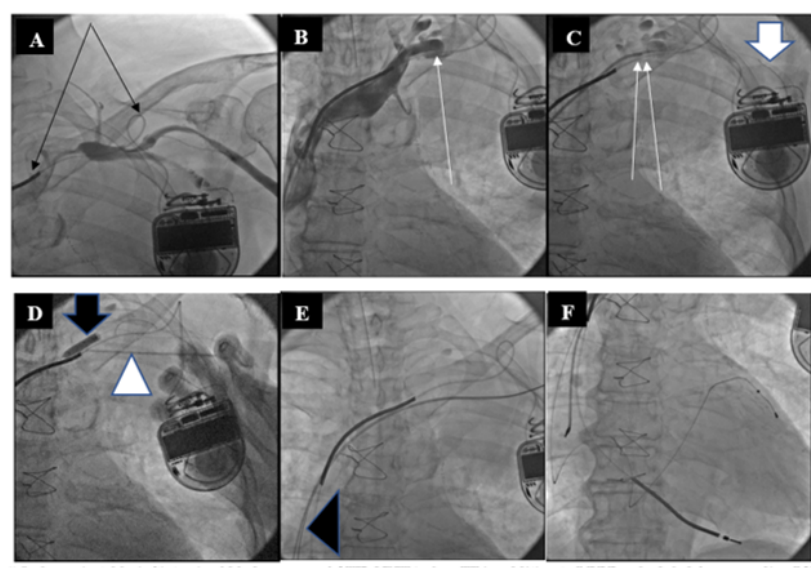

Figure 2: Case \# 5, shown in Table 1. Sixty-six old lady, a case of CHF, NYHA class III in addition to LBBB, scheduled for upgrading ICD-DR to CRT-D. (A- Anterograde ipsilateral venography which shows near complete obstruction of the subclavian vein, BRetrograde phlebography via guiding catheter that shows distal end of subclavian as well as brachiocephalic veins, C- subclavian wiring with 0.014 "through the guiding catheter. $\mathrm{D}$ - contrast filled balloon in the distal end of clavicle which is targeted by standard needle 18 $\mathrm{G}, \mathrm{E}$ - the figure shows introducing double wires into the subclavian up to brachiocephalic veins, F-Demonstration of atrial, ventricular and coronary sinus leads in the proper positions; successful implantation procedure. Long narrow arrows; the old ICD lead, long narrow white arrows: the tip of guiding catheter, Short wide white arrow: 0.014 "guiding wire, Short wide black arrow: Location of the balloon that filled with contrast, White arrowhead: The standard needle $18 \mathrm{G}$, Black arrowhead: couple guidewires that introduced into the left brachiocephalic vein).

In cases where there is a complete obstruction of the subclavian vein, several ways have been proposed, listed below, each of which has positive and negative points, and, in general, a method cannot be used to overcome this problem in all patients:

a) Use of the contralateral veins and implantation of the whole new system. The problem with this method is certainly the increase in the number of leads in the superior vena cava vein, which the Heart Rhythm Society recommends no more than four [12].

b) Lead insertion into the opposite side vein and passing it towards the pocket by creating a tunnel over the manubrium of sternum and under the subcutaneous tissue. The main problem with this method is the large size caliber lead, such as ICD lead, passing through the tunnel that has the chance of damage to the internal mammary artery.

c) In a reported method with a low number of patients, the excimer laser method of reopening a vein was suggested. Unfortunately, this technique is not available at all centres, including at our hospital centre [13].

d) Use of the supraclavicular puncture or internal jugular vein puncture. The problem with these techniques is tunnelling over the clavicular bone, which is not a good thing cosmetically. Moreover, the chance of damage to the lead is very high in the long term due to the low subcutaneous tissue content in this region [14].

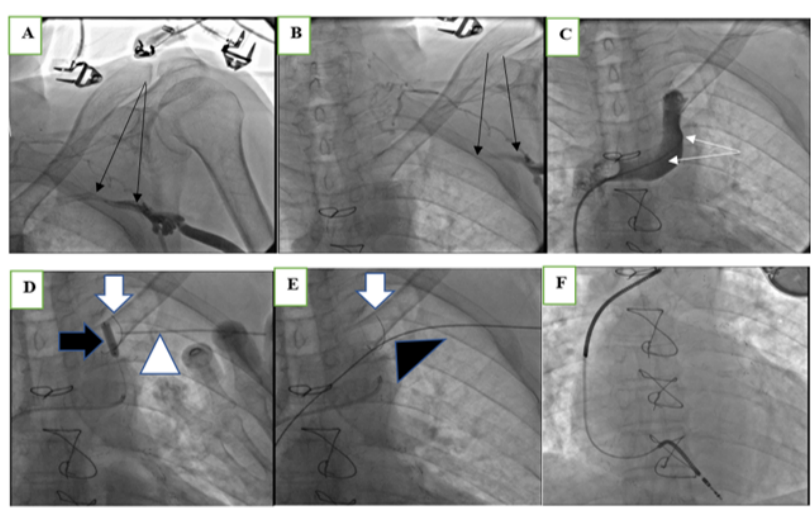

Figure 3: Case \# 11, shown in Table 1. Seventy-four old gentleman with history of several times prolonged hospital admissions, scheduled for ICD-VR implantation because of aborted sudden cardiac death. (A \& B- Ipsilateral peripheral venography demonstrates near complete occlusion of subclavian vein with faint visualization of its distal end via collaterals in the late film. CRetrograde brachiocephalic phlebography. D- Contrast filled balloon guided needle puncturing in the distal end of clavicle by use of standard needle 18-G. E- Introducing the standard $0.035 \mathrm{~J}$-wire into the vein. F- Demonstration of the positions of ventricular high voltage lead in the proper location; successful implantation procedure. Long narrow arrows; partially filled left subclavian vein, long narrow white arrows: the tip of guiding catheter, Short wide white arrow: 0.014 "guiding wire, Short wide black arrow: location of the balloon that filled with contrast White arrowhead: the standard needle $18 \mathrm{G}$, Black arrowhead: guidewire that introduced anterogradely into the left brachiocephalic vein).

e) Use of surgical technique to implant epicardial leads. It goes without saying that on the one hand, the risk of surgery to the patient, especially for patients with low EF, is imposed, and on the other hand, epicardial leads have a lower durability and short-term efficacy.

f) The use of a leadless pacemaker, which has been recently raised, is still not widely used, so its long-term performance is unclear $[15,16]$.

The use of ipsilateral peripheral vein contrast injection and then the subclavian vein puncture distal to the occlusion site, which would be a high-risk procedure with a high rate of complications such as pneumothorax as well as the possibility of damage to the subclavian artery. Other procedures such as use of excimer lasers to retrieve the old failed lead and immediate lead placement into the newly opened vein doorway or the use of iliofemoral vein puncture to introduce the lead towards the heart have been suggested in some reports but have not been promising [17].

Although in the article that has been published by Konstantinos et al. [18], it has been reported that having previous lead as well as reimplanting a pacemaker generator are risk factors for the occurrence pocket infection, it seems that according to the same study, due to the low number of needle puncturing, the shorter duration of the procedure and less hematoma formation in our patients, the chance of infection is kept to zero. However, in order to prove this claim, we should have a study with more patients and a longer follow up. As far 
as we know, for the first time, we introduced this new technique to overcome the challenge with no complication in addition to shortening the procedure time.

\section{Conclusion}

We conclude that this contrast-filled balloon guided needle puncturing technique in the presence of ipsilateral subclavian vein obstruction, is a safe and feasible method for patients who candidate for implantation or upgrading pacemakers and ICDs. It can even be used in other cases, such as patients with morbid obesity or in patients suffer from chronic kidney disease who need to undergo catheter insertion.

\section{Funding}

This work did not receive any specific grant from any funding agency in the public, commercial, or not-for-profit sector.

\section{Conflicts of Interest}

There are no conflicts of interest for the present study.

\section{References}

1. Richard HM, Selby JB, Gay SB, Tegtmeyer CJ (1992) Normal venous anatomy and collateral pathways in upper extremity venous thrombosis. Radiographics 12: 527-534.

2. Anatomy and Physiology (2016) OpenStax CNX.

3. Aubaniac R (1952) Subclavian intravenous injection: Advantages and technic. Presse Med 60: 1456.

4. Marine JE, Brinker JA (2014) Techniques of pacemaker implantation and removal. Cardiac pacing and ICDs 5: 150-210.

5. Shimada Y, Matsukawa M, Yamamoto F (2008) Subpectoral technique of pacemaker implantation-reduction of cost and length of hospital stay. J Rural Med 3: 15-18.

6. Lickfett L, Bitzen A, Arepally A, Nasir K, Wolpert C, et al. (2004) Incidence of venous obstruction following insertion of an implantable cardioverter defibrillator: A study of systematic contrast venography on patients presenting for their first elective ICD generator replacement. Europace 6: 25-31.
7. Korkeila P, Nyman K, Ylitalo A, Koistinen J, Karjalainen P, et al. (2007) Venous obstruction after pacemaker implantation. Pacing Clin Electrophysiol 30: 199-206.

8. Burri H (2015) Overcoming the challenge of venous occlusion for lead implantation. Indian Pacing Electrophysiol J 15: 110-112.

9. Rajappan K (2009) Permanent pacemaker implantation technique: Part I. Heart 95: 259-264.

10. Gonsalves CF, Eschelman DJ, Sullivan KL, DuBois N, Bonn J (2003) Incidence of central vein stenosis and occlusion following upper extremity PICC and port placement. Cardiovasc Intervent Radiol 26: 123-127.

11. Oguzkurt L, Tercan F, Yildirim S, Torun D (2005) Central venous stenosis in haemodialysis patients without a previous history of catheter placement. Eur J Radiol 55: 237-242.

12. Wilkoff BL, Love CJ, Byrd CL, Bongiorni MG, Carrillo RG, et al. (2009) Transvenous lead extraction: Heart rhythm society expert consensus on facilities, training, indications, and patient management: This document was endorsed by the American Heart Association (AHA). Heart rhythm 6: 1085-1104.

13. Sadarmin PP, Chelliah RK, Timperley J (2015) Contralateral transvenous left ventricular lead placement of implantable devices with pre-sternal tunnelling in chronically obstructed subclavian veins. Indian Pacing Electrophysiol J 15: 113-117.

14. Worley SJ, Gohn DC, Pulliam RW (2010) Excimer laser to open refractory subclavian occlusion in 12 consecutive patients. Heart Rhythm 7: 634-638.

15. Antonelli D, Freedberg NA, Turgeman Y (2010) Supraclavicular vein approach to overcoming ipsilateral chronic subclavian vein obstruction during pacemaker-ICD lead revision or upgrading. Europace 12: 1596-1599.

16. Sperzel J, Burri H, Gras D, Tjong FV, Knops RE, et al. (2015) State of the art of leadless pacing. Europace 17: 1508-1513.

17. Auricchio A, Delnoy PP, Butter C, Brachmann J, Van Erven L, et al (2014) Feasibility, safety and short-term outcome of leadless ultrasoundbased endocardial left ventricular resynchronization in heart failure patients: Results of the wireless stimulation endocardially for CRT (WiSECRT) study. Europace 16: 681-688.

18. Polyzos KA, Konstantelias AA, Falagas ME (2015) Risk factors for cardiac implantable electronic device infection: A systematic review and metaanalysis. Europace 17: 767-777. 